\title{
Community Oncologists' Decision-Making for Treatment of Older Patients With Cancer
}

\author{
Supriya G. Mohile, MD, MSª Allison Magnuson, $\mathrm{DO}^{\mathrm{a}}$; Chintan Pandya, $\mathrm{PhD}^{\mathrm{a}}$; Carla Velarde ${ }^{\mathrm{a}}$; \\ Paul Duberstein, PhD ${ }^{\mathrm{a}}$; Arti Hurria, MD ${ }^{\mathrm{b}}$; Kah Poh Loh, MDª Megan Wells ; Sandy Plumba \\ Nikesha Gilmore, PhD; ; Marie Flannery, PhDa; Marsha Wittink, MDª Ronald Epstein, $\mathrm{MD}^{\mathrm{a}}$; \\ Charles E. Heckler, $\mathrm{PhD}^{\mathrm{a}}$; Michelle Janelsins, $\mathrm{PhD}, \mathrm{MPH}^{\mathrm{a}}$; Karen Mustian, $\mathrm{PhD}, \mathrm{MPH}^{\mathrm{a}}$; \\ Judith O. Hopkins, MDc; Jane Liu, MD'; Srihari Peri, MD'; and William Dale, MD, PhD
}

\begin{abstract}
Background: This study's objectives were to describe community oncologists' beliefs about and confidence with geriatric care and to determine whether geriatric-relevant information influences cancer treatment decisions. Methods: Community oncologists were recruited to participate in 2 multisite geriatric oncology trials. Participants shared their beliefs about and confidence in caring for older adults. They were also asked to make a first-line chemotherapy recommendation (combination vs single-agent vs no chemotherapy) for a hypothetical vignette of an older patient with advanced pancreatic cancer. Each oncologist received one randomly chosen vignette that varied on 3 variables: age (72/84 years), impaired function (yes/no), and cognitive impairment (yes/no). Other patient characteristics were held constant. Logistic regression models were used to identify associations between oncologist/vignette-patient characteristics and treatment decisions. Results: Oncologist response rate was $61 \%(n=305 / 498)$. Most oncologists agreed that "the care of older adults with cancer needs to be improved" (89\%) and that "geriatrics training is essential" (72\%). However, $<25 \%$ were "very confident" in recognizing dementia or conducting a fall risk or functional assessment, and only $23 \%$ reported using the geriatric assessment in clinic. Each randomly varied patient characteristic was independently associated with the decision to treat: younger age (adjusted odds ratio [aOR], 5.01; 95\% $\mathrm{Cl}, 2.73-9.20$ ), normal cognition ( $\mathrm{aOR}, 5.42 ; 95 \% \mathrm{Cl}, 3.01-9.76)$, and being functionally intact (aOR, 3.85; $95 \% \mathrm{Cl}, 2.12-7.00)$. Accounting for all vignettes across all scenarios, 161 oncologists (52\%) said they would offer chemotherapy. All variables were independently associated with prescribing single-agent over combination chemotherapy (older age: aOR, 3.22; 95\% Cl 1.43-7.25, impaired cognition: aOR, 3.13; 95\% Cl, 1.36-7.20, impaired function: aOR, 2.48; $95 \% \mathrm{Cl}, 1.12-5.72$ ). Oncologists' characteristics were not associated with decisions about providing chemotherapy. Conclusion: Geriatric-relevant information, when available, strongly influences community oncologists' treatment decisions.
\end{abstract}

J Natl Compr Canc Netw 2018;16(3):301-309 doi: 10.6004/jnccn.2017.7047

From a James Wilmot Cancer Center, University of Rochester, Rochester,

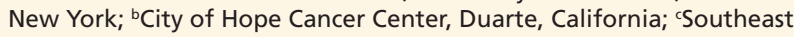
Clinical Oncology Research (SCOR) Consortium NCl Community Oncology Research Program (NCORP), Winston-Salem, North Carolina; ${ }^{d} H e a r t l a n d$ Cancer Research NCORP, Decatur, Illinois; and eDelaware/Christiana Care NCORP, Newark, Delaware.

Submitted August 10, 2017; accepted for publication October 9, 2017. Dr. Hurria has disclosed that she has received grant or research support from Celgene and Novartis, and has served as a consultant for Boehringer Ingelheim, Pierian Biosciences, and MJH Healthcare Holdings. The remaining authors have disclosed that they have no financial interests, arrangements, affiliations, or commercial interests with the manufacturers of any products discussed in this article or their competitors.

This work was funded through a PCORI program contract (4634), UG1 CA189961 from the $\mathrm{NCl}$, and R01 CA177592 from the $\mathrm{NCl}$. This work was made possible by the generous donors to the $\mathrm{WCl}$ geriatric oncology philanthropy fund. All statements in this report, including its findings and conclusions, are solely those of the authors, do not necessarily represent the official views of the funding agencies, and do not necessarily represent the views of PCORI, its Board of Governors, or Methodology Committee.

Author contributions: Study concept and design: Mohile, Magnuson, Pandya, Velarde, Hurria, Heckler, Dale. Data acquisition: Mohile, Magnuson, Velarde, Hurria, Wells, Plumb, Gilmore, Hopkins, Liu, Peri, Dale. Data analysis and interpretation: All authors. Manuscript preparation: All authors. Critical revision: All authors.

Correspondence: Supriya G. Mohile, MD, MS, James P. Wilmot Cancer Center, University of Rochester, 601 Elmwood Avenue, Box 704, Rochester, NY 14642. E-mail: supriya_mohile@urmc.rochester.edu 
As the baby boomer generation in the United States ages, the number of older patients with cancer is increasing. A $67 \%$ increase in cancer incidence is projected in those individuals aged $\geq 65$ years, compared with an $11 \%$ increase among younger adults. ${ }^{1,2}$ Older patients with cancer have a higher prevalence of comorbidities, geriatric syndromes, and disabilities than younger patients and older patients without cancer. ${ }^{3,4}$ Older patients with conditions other than cancer also carry a high risk of developing significant chemotherapy toxicity, functional and cognitive loss, and physical decline while on treatment. ${ }^{5,6}$ The underrepresentation of older adults in clinical trials places them at risk of receiving inappropriate undertreatment or overtreatment for their cancer, leading to disparities in outcomes. ${ }^{5,7-9}$ For example, fit older patients are less likely to receive evidence-based standard-of-care cancer treatment than younger patients, whereas older patients with both cancer and comorbid conditions are too often treated with therapies with high toxicity rates and low likelihood of benefit. $^{10}$

A recent Institute of Medicine report acknowledged that our current systems are ill-prepared to care for the most vulnerable patients with cancerthose who are older (especially those aged $\geq 80$ years) and those who have health conditions other than cancer. ${ }^{11}$ Because older patients with cancer receiving treatment are often seen by their oncology teams more frequently than by their primary care providers (PCPs), ${ }^{12}$ community oncology practices should be equipped to recognize common age-related concerns. Despite the rapidly increasing population of older patients with cancer, most oncologists have received little geriatrics training, and therefore common aging-related conditions that influence outcomes are rarely detected. ${ }^{13-16}$

In this study, community oncologists were recruited to participate in 2 nationwide, geriatric oncology clinical trials in the University of Rochester Cancer Center's NCI Community Oncology Research Program (URCC NCORP). During enrollment, they completed a survey regarding their beliefs about and confidence in providing geriatric care. ${ }^{17}$ Similar to other studies, ${ }^{18-21}$ randomized vignettes were used to assess whether clinical factors influenced their cancer treatment decision-making. This study, however, is the first that assesses how common geriatric factors (ie, function and cognition) affect decisions related to first-line chemotherapy in older patients with advanced cancer.

\section{Methods}

\section{Participants}

Participants were community oncologists recruited for 2 geriatric oncology studies (URCC 13059 [ClinicalTrials.gov identifier: NCT02054741] and/ or URCC 13070 [NCT02107443]). Both studies involve a geriatric assessment (GA), which is a battery of validated tools to evaluate health status in multiple domains, including function, physical performance, depression, falls, and cognition, ${ }^{22}$ and evaluate whether providing a GA summary and targeted recommendations to community oncologists can improve outcomes in older patients with cancer.

Community oncologists were eligible to participate if they practiced at an NCI-funded NCORP affiliate site, their NCORP affiliate had IRB approval for either study, and they were not planning on leaving the practice. Oncologists were provided with a link to a survey via e-mail, using REDCap, a secure Web-based electronic data capture tool. If not completed, a paper survey option was offered. Oncologists were required to complete the baseline survey before participating in procedures of the main study. A waiver of consent was approved by the University of Rochester IRB for enrollment of oncologists.

\section{Survey Design}

The "Physician Baseline Survey" had 3 components: (1) oncologist demographics and practice characteristics, (2) oncologist ratings of their beliefs about and confidence with management of common geriatric issues, and (3) 1 of 8 randomly assigned clinical vignettes. The beliefs and confidence questions were developed by Cancer and Aging Research Group investigators (A.M., S.G.M., W.D.) and were modeled on a previously published survey. ${ }^{17}$ In accordance with prior studies, ${ }^{18,21}$ a vignette with a shared scenario was created describing an older female patient with metastatic pancreatic cancer presenting to her oncologist for a decision regarding first-line chemotherapy. A vignette of a patient with metastatic disease was selected to assess how geriatric factors may influence the weighing of risks and benefits of chemotherapy for frail older patients with limited life expectancies. The patient was an older woman who 
lived alone with a history of well-controlled hypertension, hyperlipidemia, and osteoarthritis; moderate fatigue (ECOG performance status [PS], 1); and an estimated life expectancy of $\leq 6$ months, with no other symptoms from her cancer. Using this information as a base, 8 patient vignettes were created with 3 varied factors: age ( 72 vs 84 years), cognitive status (no impairment vs moderate impairment requiring assistance with finances and low Mini-Mental State Examination [MMSE; score of 15]), and functional status (no impairment vs impairment that included falls and deficits in instrumental activities of daily living [IADLs]). These factors were chosen because they are among the most important predictors of poor outcomes in older patients and are associated with frailty. ${ }^{5,23-27}$ In order to reduce bias (eg, physician answer for one vignette influences responses to others), a randomization scheme was developed so that each enrolled physician would receive 1 of the 8 vignettes.

\section{Statistical Analysis}

Descriptive statistics were used to describe physician demographics. Descriptive statistics were also used for the Likert scale questions regarding beliefs about and confidence with geriatrics, with interquartile range, mean, and median reported for each item. Bivariate associations between patient and physician characteristics and decision to treat with chemotherapy were analyzed with chi-square tests for categorical variables and $t$-tests for continuous variables. A total summary score was calculated for physician beliefs and physician confidence, and each score was categorized into tertiles due to a skewed distribution.

Logistic regression was performed to determine the independent association of the 3 varied vignettepatient characteristics (age, cognitive status, functional status) with primary outcome: whether oncologists would recommend treatment with first-line chemotherapy (yes/no) (Model A). In cases when chemotherapy was recommended, a second regression was conducted, predicting whether oncologists recommended single-agent chemotherapy or combination chemotherapy (Model B). Both models controlled for physician characteristics. Physician characteristics included sex (male/female), race (white/ nonwhite), number of patients seen per day, and years in practice. A $P$ value of $<.05$ was considered significant for all analyses. Analyses were performed using SAS 9.4 (SAS Institute, Cary NC).

\section{Results}

Of 498 surveys sent to eligible community oncologists in the URCC NCORP network, 305 consented to one or both of the studies (61\% response rate). The oncologists were associated with 58 individual practice sites.

\section{Oncologist Demographics and Practice Characteristics}

Participants $(\mathrm{N}=305)$ had a mean age of 49 years, and most were male $(71 \%)$, white $(65 \%)$, and nonHispanic (94\%) (Table 1). Most were board certified in oncology $(95 \%)$ and had a mean of 15 years in practice post-oncology fellowship. On average, oncologists saw 17 patients per day and were clinically active 4 days of the week.

\section{Oncologist Perspectives Regarding Geriatrics Care}

Most oncologists agreed that "there should be more clinical trials designed specifically for the elderly" (90\%) and "the medical care of older adults

\begin{tabular}{|c|c|}
\hline \multicolumn{2}{|l|}{ Characteristic } \\
\hline Mean age (range), y & $48.6(29-76)$ \\
\hline \multicolumn{2}{|l|}{ Sex } \\
\hline Male & $70.8 \%$ \\
\hline Female & $29.2 \%$ \\
\hline \multicolumn{2}{|l|}{ Race } \\
\hline White & $65.0 \%$ \\
\hline African American/Black & $2.7 \%$ \\
\hline American Indian/Alaskan Native & $0.3 \%$ \\
\hline Asian & $31.3 \%$ \\
\hline Native Hawaiian/Other Pacific Islander & $0.7 \%$ \\
\hline \multicolumn{2}{|l|}{ Ethnicity } \\
\hline Hispanic/Latino & $2.0 \%$ \\
\hline Non-Hispanic & $94.4 \%$ \\
\hline Unknown & $3.6 \%$ \\
\hline \multicolumn{2}{|l|}{ Board certified in oncology } \\
\hline Yes & $95.1 \%$ \\
\hline Mean years in practice (range) & $14.6(0.5-44)$ \\
\hline Mean number of patients seen per day (range) & $17.3(2-45)$ \\
\hline
\end{tabular}


with cancer needs to be improved" (89\%) (Table 2). Many agreed that they would "appreciate additional training in topics related to the care of older adults with cancer" (79\%). Most reported routinely asking patients about falls (70\%). Much less commonly, oncologists agreed that they "frequently order home safety evaluations" (41\%) or "enlist the help of a social worker with specialized geriatrics training" (31\%). Only 23\% agreed they "use standardized GA tools to help make decisions about treatment."

\section{Oncologist Ratings of Confidence in Geriatric Care}

Most oncologists felt "quite to very confident" when it came to discussing advanced directives (84\%), preventing and managing osteoporosis (72\%), and

\begin{tabular}{|c|c|c|c|}
\hline & Agree $^{c}$ & Disagree $^{d}$ & Neutrale \\
\hline $\begin{array}{l}\text { I believe there should be } \\
\text { more clinical trials designed } \\
\text { specifically for older patients } \\
\text { with cancer }\end{array}$ & $90 \%$ & $3 \%$ & $7 \%$ \\
\hline $\begin{array}{l}\text { I believe that the medical care } \\
\text { of older adults with cancer } \\
\text { needs to be improved }\end{array}$ & $89 \%$ & $3 \%$ & $8 \%$ \\
\hline $\begin{array}{l}\text { I strive to reduce the number } \\
\text { of medications that my older } \\
\text { patients are taking }\end{array}$ & $81 \%$ & $4 \%$ & $15 \%$ \\
\hline $\begin{array}{l}\text { I would appreciate additional } \\
\text { training in topics related to the } \\
\text { care of older adults with cancer }\end{array}$ & $79 \%$ & $4 \%$ & $17 \%$ \\
\hline $\begin{array}{l}\text { I believe that geriatric training } \\
\text { is essential for the care of older } \\
\text { adults with cancer }\end{array}$ & $72 \%$ & $9 \%$ & $18 \%$ \\
\hline $\begin{array}{l}\text { I routinely ask my patients if } \\
\text { they have a history of recent } \\
\text { falls }\end{array}$ & $70 \%$ & $14 \%$ & $16 \%$ \\
\hline $\begin{array}{l}\text { I frequently order home safety } \\
\text { evaluations for my older } \\
\text { patients }\end{array}$ & $41 \%$ & $35 \%$ & $25 \%$ \\
\hline $\begin{array}{l}\text { I frequently enlist the help of a } \\
\text { social worker with specialized } \\
\text { geriatrics training }\end{array}$ & $31 \%$ & $37 \%$ & $32 \%$ \\
\hline $\begin{array}{l}\text { I use standardized geriatric } \\
\text { assessment tools to help make } \\
\text { decisions about treatment }\end{array}$ & $23 \%$ & $49 \%$ & $29 \%$ \\
\hline
\end{tabular}

Based on a Likert scale, where 1 = strongly disagree, 2 = somewhat disagree, $3=$ neutral, $4=$ somewhat agree, and $5=$ strongly agree. aSome percentages may not total $100 \%$ due to rounding.

${ }^{\text {b} A l l ~ q u e s t i o n s ~ w i t h ~}<5$ missing values.

cPercent "agree" was calculated using the sum of physicians who chose a 4 or 5 on the Likert scale.

"Percent "disagree" was calculated using the sum of physicians who chose a 1 or 2 on the Likert scale.

ePercent "neutral" was calculated using physicians who chose a 3 on the Likert scale. determining patients' social support/living experiences (53\%) (Table 3). Confidence was lower for other skills: $\leq 25 \%$ were "quite to very confident" in conducting and evaluating a functional assessment; recognizing, evaluating, and treating dementia; and conducting an assessment and intervention for falls.

\section{Vignette Responses}

Chemotherapy Choices: Accounting for all vignettes across all scenarios, 161 oncologists (52\%) said they would offer at least some form of chemotherapy. Of these, $64.6 \%(n=104)$ would offer single-agent chemotherapy, such as gemcitabine or capecitabine, and $35.4 \%(n=57)$ would offer multiagent chemotherapy, such as FOLFIRINOX or gemcitabine/nab-paclitaxel.

Bivariate Analyses: A consistent relationship was seen between vignette-patient characteristics and the decision to recommend chemotherapy (Table 4 and Figure 1). The proportion of oncologists who recommended any chemotherapy decreased with older patient age, cognitive impairment, and functional impairment. At the extremes, most oncologists (97\%) randomized to vignette 1 (younger age and no functional or cognitive impairment) would recommend chemotherapy, whereas only a minority (14\%) randomized to vignette 8 (older age, functional impairment, and cognitive impairment) would recommend chemotherapy. There was a general "dose-response" relationship, with older age and greater geriatric deficits leading to less aggressive therapy choices.

For the patients for whom chemotherapy was recommended, doublet chemotherapy was preferred over monotherapy only for the vignette-patient who was aged 72 years without functional or cognitive impairment (63\% vs 38\%). For the remainder of the vignette-patients, monotherapy was strongly preferred.

Older age ( 84 years), impaired function, and cognitive impairment were all associated with the decision to not recommend chemotherapy $(P<.01$ for all). For vignette-patients for whom chemotherapy was recommended, there was a significant relationship between older age and a higher likelihood of recommending single-agent therapy $(P<.01)$. There was also a significant association between impaired functional and cognitive status of the vignette-patient and the likelihood of recommendation for singleagent therapy $(P<.01)$. 
Treatment Decision-Making for Older Patients

Table 3. Oncologist Ratings of Confidence in Geriatrics ${ }^{\mathrm{a}, \mathrm{b}}$

\begin{tabular}{|c|c|c|c|c|}
\hline & $\begin{array}{l}\text { Quite to Very } \\
\text { Confident }^{c}\end{array}$ & $\begin{array}{l}\text { Slightly to } \\
\text { Moderately }_{\text {Confident }^{\mathrm{d}}}\end{array}$ & $\begin{array}{l}\text { Not at all } \\
\text { Confident }\end{array}$ & Mean (median), $\mathrm{n}$ \\
\hline Discuss advance directives & $84 \%$ & $15 \%$ & $0 \%$ & $4.3(4)$ \\
\hline Prevent and manage osteoporosis & $72 \%$ & $26 \%$ & $2 \%$ & $3.9(4)$ \\
\hline Determine patient's social support/living experiences & $53 \%$ & $45 \%$ & $2 \%$ & $3.5(4)$ \\
\hline Recognize, evaluate, and treat depression & $47 \%$ & $49 \%$ & $4 \%$ & $3.4(3)$ \\
\hline Make recommendations for rehabilitation & $41 \%$ & $54 \%$ & $5 \%$ & $3.2(3)$ \\
\hline Recognize, evaluate, and treat delirium & $39 \%$ & $54 \%$ & $6 \%$ & $3.2(3)$ \\
\hline Assess nutritional status & $37 \%$ & $61 \%$ & $2 \%$ & $3.2(3)$ \\
\hline Conduct and evaluate a functional assessment & $25 \%$ & $65 \%$ & $10 \%$ & $2.8(3)$ \\
\hline Recognize, evaluate, and treat dementia & $23 \%$ & $69 \%$ & $8 \%$ & $2.8(3)$ \\
\hline Conduct an assessment of and an intervention for falls & $21 \%$ & $65 \%$ & $14 \%$ & $2.6(3)$ \\
\hline Recognize, evaluate, and treat urinary incontinence & $21 \%$ & $64 \%$ & $15 \%$ & $2.7(3)$ \\
\hline
\end{tabular}

Based on a Likert scale, where $1=$ not at all confident, $2=$ slightly confident, $3=$ moderately confident, $4=$ quite confident, and $5=$ very confident. aSome percentages may not total $100 \%$ due to rounding.

bAll values with $<3$ missing values.

"Percent "quite to very confident" was calculated using the sum of physicians who chose a 4 or 5 on the Likert scale.

dPercent "slightly to moderately confident" was calculated using the sum of physicians who chose a 2 or 3 on the Likert scale.

epercent "not at all confident" was calculated using physicians who chose a 1 on the Likert scale.

No association was found between physician beliefs about and confidence in caring for older adults and the decision to treat with chemotherapy. Total summary scores of beliefs (Table 2) and confidence (Table 3) were not associated with chemotherapy decisions (decision to treat with chemotherapy or intensity of treatment in those for whom chemotherapy was recommended).

Multivariable Analyses: Oncologist demographic and practice characteristics were not associated with the decision to treat with chemotherapy (Table 5). Varied patient characteristics were independently and strongly associated with the decision to give chemotherapy: younger age (adjusted odds ratio [aOR], 5.01; 95\% CI, 2.73-9.20), no cognitive impairment (aOR, 5.42; 95\% CI 3.01-9.76), and no functional impairment (aOR, 3.85; 95\% CI, 2.12-7.00). Older age (aOR, 3.22; 95\% CI, 1.43-7.25), impaired cognition (aOR, 3.13; 95\% CI, 1.36-7.20), and functional impairment (aOR, 2.48; 95\% CI, 1.12-5.46) were independently associated with prescribing single-agent over multiagent chemotherapy.

\section{Discussion}

In this study, we found that community oncologists incorporate patient age, functional impairment, and cognitive impairment into the decision-making process for cancer treatment in older adults. Despite the high prevalence of cognitive and functional decline in older adults with cancer, ${ }^{4} \leq 25 \%$ of community oncologists rated themselves as "very confident" in assessment and interventions for function, falls, and dementia. To our knowledge, this is the first study to show that, whereas only a minority of community oncologists feels confident in assessing and intervening on geriatric issues, most use this information in clinical decision-making. However, this study also shows that there is significant variability in how geriatric issues are incorporated into decision-making for older patients who are not clearly fit or frail.

Older age was independently associated with chemotherapy decisions, which may result from limited evidence of the risks and benefits of chemotherapy for older patients. For advanced pancreatic cancer, multidrug chemotherapy regimens (eg, FOLFIRINOX, gemcitabine/nab-paclitaxel) have shown survival benefits. ${ }^{28-30}$ The phase III trial of FOLFIRINOX versus gemcitabine alone only included patients with an ECOG PS of 0 or 1 and excluded those aged $\geq 76$ years, ${ }^{28}$ with age $>65$ years being significantly associated with worse survival. ${ }^{29}$ Although the phase III trial of gemcitabine/nab-paclitaxel versus gemcitabine alone did not have an upper age limit (42\% of patients enrolled were $\geq 65$ years, with only $10 \%$ of patients $\geq 75$ years), older age was associated with worse survival. ${ }^{31}$ In addition, the grade $3 / 4$ toxicity rate for these regimens in the clinical trial population is $>50 \% .{ }^{28-31}$ Toxicities are more severe and prevalent in the non-clinical trial population; in one study of 46 patients who received FOLFIRINOX, 54\% were hos- 


\section{Table 4. Percentage of Oncologists Recommending Chemotherapy for Each Patient Vignette}

\section{Patient Vignette}

The patient (initials) is a -year-old woman with a history of well-controlled hypertension, hyperlipidemia, and osteoarthritis, who is referred for evaluation of metastatic pancreatic cancer. She has a $3-\mathrm{cm}$ pancreatic adenocarcinoma with metastatic disease to the liver. Based on her cancer diagnosis, her estimated life expectancy is $\leq 6$ months. She currently reports moderate fatigue, which is impacting her daily activities (ECOG PS 1 ), but denies any other symptoms from her cancer. She currently lives alone.

\begin{tabular}{|c|c|c|c|c|}
\hline $\begin{array}{l}\text { Vignette Number } \\
(\mathrm{N}=303)^{\mathrm{b}}\end{array}$ & Varied Factors & $\begin{array}{l}\text { Explanation of } \\
\text { Varied Factors }\end{array}$ & \multicolumn{2}{|c|}{$\begin{array}{c}\text { Oncologists } \\
\text { Recommending Chemotherapy }\end{array}$} \\
\hline \multirow{3}{*}{$\begin{array}{l}\text { Vignette } 1 \\
(n=34)\end{array}$} & \multirow{3}{*}{$\begin{array}{l}\text { A.M. is a } 72 \text {-year-old woman. She independently performs all } \\
\text { ADLs and IADLs. She denies any memory problems or history } \\
\text { of dementia. }\end{array}$} & Younger & \multirow[t]{3}{*}{$97 \%$} & \multirow{3}{*}{$\begin{array}{l}\text { Multiagent: } 63 \% \\
\text { Monotherapy: } 38 \%\end{array}$} \\
\hline & & $\begin{array}{l}\text { No functional } \\
\text { impairment }\end{array}$ & & \\
\hline & & $\begin{array}{l}\text { No cognitive } \\
\text { impairment }\end{array}$ & & \\
\hline \multirow{3}{*}{$\begin{array}{l}\text { Vignette } 2 \\
(n=39)\end{array}$} & \multirow{3}{*}{$\begin{array}{l}\text { B.L. is a } 72 \text {-year-old woman. She independently performs } \\
\text { all ADLs but requires assistance with some IADLs, including } \\
\text { housekeeping and grocery shopping. She has had } 3 \text { falls in } \\
\text { the past } 6 \text { months, and sustained an injury requiring an ER } \\
\text { visit during one episode. She denies any memory problems or } \\
\text { history of dementia. }\end{array}$} & Younger & \multirow[t]{3}{*}{$74 \%$} & \multirow{3}{*}{$\begin{array}{l}\text { Multiagent: } 41 \% \\
\text { Monotherapy: } 59 \%\end{array}$} \\
\hline & & $\begin{array}{l}\text { Functional } \\
\text { impairment }\end{array}$ & & \\
\hline & & $\begin{array}{l}\text { No cognitive } \\
\text { impairment }\end{array}$ & & \\
\hline \multirow{3}{*}{$\begin{array}{l}\text { Vignette } 3 \\
(n=31)\end{array}$} & \multirow{3}{*}{$\begin{array}{l}\text { C.K. is a } 72 \text {-year-old woman. She independently performs all } \\
\text { ADLs and most IADLs. She requires assistance with managing } \\
\text { household finances due to memory problems. Cognitive } \\
\text { testing is performed and her cognition is found to be } \\
\text { impaired (MMSE 15).d }\end{array}$} & Younger & \multirow[t]{3}{*}{$61 \%$} & \multirow{3}{*}{$\begin{array}{l}\text { Multiagent: } 39 \% \\
\text { Monotherapy: } 61 \%\end{array}$} \\
\hline & & $\begin{array}{l}\text { No functional } \\
\text { impairment }\end{array}$ & & \\
\hline & & $\begin{array}{l}\text { Cognitive } \\
\text { impairment }\end{array}$ & & \\
\hline \multirow{3}{*}{$\begin{array}{l}\text { Vignette } 4 \\
(n=27)\end{array}$} & \multirow{3}{*}{$\begin{array}{l}\text { D.J. is a } 72 \text {-year-old woman. She independently performs } \\
\text { all ADLs but requires assistance with some IADLs, including } \\
\text { housekeeping, grocery shopping, and managing finances. } \\
\text { She has had } 3 \text { falls in the past } 6 \text { months, and sustained an } \\
\text { injury requiring an ER visit during one episode. Cognitive } \\
\text { testing is performed and her cognition is found to be } \\
\text { impaired (MMSE 15). }{ }^{\text {. }}\end{array}$} & Younger & \multirow[t]{3}{*}{$56 \%$} & \multirow{3}{*}{$\begin{array}{l}\text { Multiagent: } 13 \% \\
\text { Monotherapy: } 87 \%\end{array}$} \\
\hline & & $\begin{array}{l}\text { Functional } \\
\text { impairment }\end{array}$ & & \\
\hline & & $\begin{array}{l}\text { Cognitive } \\
\text { impairment }\end{array}$ & & \\
\hline \multirow{3}{*}{$\begin{array}{l}\text { Vignette } 5 \\
(\mathrm{n}=39)\end{array}$} & \multirow{3}{*}{$\begin{array}{l}\text { E.K. is an } 84 \text {-year-old woman. She independently performs all } \\
\text { ADLs and IADLs. She denies any memory problems or history } \\
\text { of dementia. }\end{array}$} & Older & \multirow[t]{3}{*}{$85 \%$} & \multirow{3}{*}{$\begin{array}{l}\text { Multiagent: } 38 \% \\
\text { Monotherapy: } 62 \%\end{array}$} \\
\hline & & $\begin{array}{l}\text { No functional } \\
\text { impairment }\end{array}$ & & \\
\hline & & $\begin{array}{l}\text { No cognitive } \\
\text { impairment }\end{array}$ & & \\
\hline \multirow{3}{*}{$\begin{array}{l}\text { Vignette } 6 \\
(n=41)\end{array}$} & \multirow{3}{*}{$\begin{array}{l}\text { F.H. is an } 84 \text {-year-old woman. She independently performs } \\
\text { all ADLs but requires assistance with some IADLs, including } \\
\text { housekeeping and grocery shopping. She has had } 3 \text { falls in } \\
\text { the past } 6 \text { months, and sustained an injury requiring an ER } \\
\text { visit during one episode. She denies any memory problems or } \\
\text { history of dementia. }\end{array}$} & Older & \multirow[t]{3}{*}{$44 \%$} & \multirow{3}{*}{$\begin{array}{l}\text { Multiagent: } 18 \% \\
\text { Monotherapy: } 82 \%\end{array}$} \\
\hline & & $\begin{array}{l}\text { Functional } \\
\text { impairment }\end{array}$ & & \\
\hline & & $\begin{array}{l}\text { No cognitive } \\
\text { impairment }\end{array}$ & & \\
\hline \multirow{3}{*}{$\begin{array}{l}\text { Vignette } 7 \\
(n=43)\end{array}$} & \multirow{3}{*}{$\begin{array}{l}\text { G.S. is an } 84 \text {-year-old woman. She independently performs } \\
\text { all ADLs and most IADLs. She only requires assistance with } \\
\text { managing household finances due to memory problems. } \\
\text { Cognitive testing is performed and her cognition is found to } \\
\text { be impaired (MMSE 15). }\end{array}$} & Older & \multirow[t]{3}{*}{$37 \%$} & \multirow{3}{*}{$\begin{array}{l}\text { Multiagent: } 19 \% \\
\text { Monotherapy: } 81 \%\end{array}$} \\
\hline & & $\begin{array}{l}\text { No functional } \\
\text { impairment }\end{array}$ & & \\
\hline & & $\begin{array}{l}\text { Cognitive } \\
\text { impairment }\end{array}$ & & \\
\hline \multirow{3}{*}{$\begin{array}{l}\text { Vignette } 8 \\
(n=49)\end{array}$} & \multirow{3}{*}{$\begin{array}{l}\text { H.T. is an } 84 \text {-year-old woman. She independently performs } \\
\text { ADLs but requires assistance with some IADLs, including } \\
\text { housekeeping, grocery shopping, and managing finances. } \\
\text { She has had } 3 \text { falls in the past } 6 \text { months, and sustained an } \\
\text { injury requiring an ER visit during one episode. Cognitive } \\
\text { testing is performed and her cognition is found to be } \\
\text { impaired (MMSE 15).d }\end{array}$} & Older & \multirow[t]{3}{*}{$14 \%$} & \multirow{3}{*}{$\begin{array}{l}\text { Multiagent: } 0 \% \\
\text { Monotherapy: } 100 \%\end{array}$} \\
\hline & & $\begin{array}{l}\text { Functional } \\
\text { impairment }\end{array}$ & & \\
\hline & & $\begin{array}{l}\text { Cognitive } \\
\text { impairment }\end{array}$ & & \\
\hline
\end{tabular}

Bolded items are characteristics that were varied systematically between vignettes.

Abbreviations: ADLs, activities of daily living; ER, emergency room; IADLs, instrumental activities of daily living; MMSE, Mini-Mental State Examination; PS, performance status.

aEach physician was randomized to one vignette as part of the survey; 2 physicians did not provide a response.

bPhysician who complete vignette questions.

'Doublet versus monotherapy answer may not total $100 \%$ due to missing data.

${ }^{d}$ A MMSE score of 15 is indicative of problems with learning new information, recognizing close relatives, personality changes, and behavior disorders. 


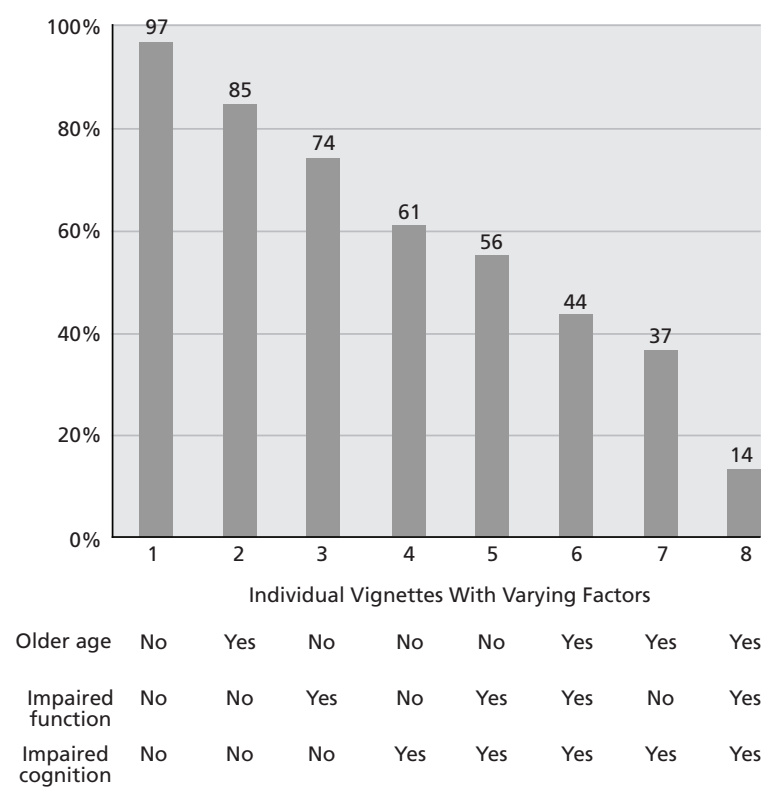

Figure 1. Percentage of oncologists who recommended chemotherapy by varied factors in vignettes.

pitalized for sepsis and $7 \%$ died from treatment. ${ }^{32}$ Hesitancy to provide multiagent chemotherapy regimens to older patients, even those who are fit, likely stems from oncologists' concerns about the ability of older adults to tolerate these regimens. ${ }^{33}$ Conversely, many oncologists continue to offer single-agent regimens to older patients with cognitive or functional impairments (often unrecognized without a formal GA) ${ }^{15}$ despite modest benefit. This study demonstrates that lack of evidence-based data to support cancer treatment plans in older patients leads to significant variability in treatment decision-making. . $^{21,34-37}$

In this study, physician beliefs about or confidence in their evaluation and management of age-related health issues did not influence chemotherapy decisions. However, most oncologists believe that geriatric training is essential for the care of older patients with cancer and would appreciate additional training in age-related topics. Most oncologists reported lower levels of confidence in assessing and intervening in certain geriatric syndromes-particularly dementia, functional decline, and risk for falls-precisely the areas that were found in the vignettes to influence treatment choices. These results mirror those from other studies. Among 758 PCPs, there was significant interest in learning more about dementia, urinary incontinence, and functional assessment. ${ }^{17}$ A study by Maggiore et $\mathrm{al}^{16}$ investigated perceptions toward ge- riatrics among University of Chicago hematology/ oncology fellows. Underrecognition of geriatric syndromes was identified as a gap in knowledge, as well as underappreciation of the complexity of geriatric oncology cases. Most perceived a lack of dedicated formal instruction on older patients with cancer during their fellowship. In a study by Moy et al, ${ }^{14}$ oncologist members of ASCO reported that the mandatory integration of key principles of geriatrics into oncology training was a high priority. The investigators made recommendations to include geriatric training in the fellowship curriculum and to develop geriatric oncology modules for maintenance of certification training.

Only 23\% of community oncologists report using standardized GA tools in clinical practice. GA assists with the capture of age-related factors (ie, cognitive impairment and functional status) known to affect morbidity and mortality in older patients with cancer that are often not recognized in clinical practice. ${ }^{15,22,38}$ In addition, GA has been shown to predict tolerance to treatment and overall survival, and specific variables captured by GA can predict chemotherapy toxicity in older patients with cancer. ${ }^{5,26,39,40}$ Consequently, multiple guidelines, including those by NCCN, support the use of a GA in older patients with cancer to identify patients at risk for adverse outcomes. ${ }^{41}$ Falls and cognitive impairment are associated with chemotherapy toxicity in older patients. ${ }^{5,26}$ Although GA has demonstrated feasibility in the clinical oncology setting, ${ }^{42-45}$ oncologists have been slow to adopt it, which may reflect lack of knowledge, training, and systematic barriers.

In this study, GA information (eg, IADL impairments, falls, low MMSE score indicating significant cognitive impairment), when provided in vignettes, was used to guide cancer treatment recommendations. Other studies have demonstrated that GA information can influence an oncologist's treatment decisions in older patients with cancer. ${ }^{46-48}$ In 6 of the 10 studies in a systematic review by Hamaker et $\mathrm{al},{ }^{47}$ the initial cancer treatment plan was modified in $39 \%$ of patients after GA evaluation. Nononcologic interventions based on the GA were recommended for a median of $83 \%$ of patients. ${ }^{47}$ Nononcologic interventions included nutritional interventions, further evaluation and management of cognitive status, interventions for mobility and falls, and interventions for minimizing polypharmacy. ${ }^{47}$ Oncologists use of geriatric factors in treatment decisions for patients in the 
Mohile et al

\begin{tabular}{|c|c|c|}
\hline Variables & aOR & $95 \% \mathrm{Cl}$ \\
\hline \multicolumn{3}{|c|}{$\begin{array}{l}\text { Model } A^{\text {a: }} \text { Decision to recommend chemotherapy vs no } \\
\text { chemotherapy }\end{array}$} \\
\hline \multicolumn{3}{|l|}{ Physician characteristics } \\
\hline Age, y & 1.00 & $0.93-1.08$ \\
\hline \multicolumn{3}{|l|}{ Sex } \\
\hline Female & 1 (Ref) & \\
\hline Male & 0.85 & $0.43-1.66$ \\
\hline \multicolumn{3}{|l|}{ Race } \\
\hline Nonwhite & 1 (Ref) & \\
\hline White & 0.76 & $0.39-1.46$ \\
\hline Number of years in practice & 1.01 & $0.94-1.09$ \\
\hline Number of patients seen per day & 1.01 & $0.97-1.06$ \\
\hline $\begin{array}{l}\text { Number of days per week seeing } \\
\text { patients }\end{array}$ & 1.24 & $0.87-1.76$ \\
\hline \multicolumn{3}{|l|}{ Vignette-patient characteristics } \\
\hline \multicolumn{3}{|l|}{ Age, y } \\
\hline 72 & $5.01^{\mathrm{b}}$ & $2.73-9.20$ \\
\hline 84 & 1 (Ref) & \\
\hline \multicolumn{3}{|l|}{ Cognitive impairment } \\
\hline No & $5.42^{\mathrm{b}}$ & $3.01-9.76$ \\
\hline Yes & 1 (Ref) & \\
\hline \multicolumn{3}{|l|}{ Functional impairment } \\
\hline No & $3.85^{\mathrm{b}}$ & $2.12-7.00$ \\
\hline Yes & 1 (Ref) & \\
\hline \multicolumn{3}{|c|}{$\begin{array}{l}\text { Model } B^{c} \text { : Decision to recommend single-agent vs combination } \\
\text { therapy }\end{array}$} \\
\hline \multicolumn{3}{|l|}{ Physician characteristics } \\
\hline Age (years) & 1.01 & $0.92-1.11$ \\
\hline \multicolumn{3}{|l|}{ Sex } \\
\hline Female & 1 (Ref) & \\
\hline Male & 1.00 & $0.39-2.60$ \\
\hline \multicolumn{3}{|l|}{ Race } \\
\hline Nonwhite & 1 (Ref) & \\
\hline White & 1.28 & $0.54-3.08$ \\
\hline Number of years in practice & 1.00 & $0.91-1.10$ \\
\hline Number of patients seen per day & 1.01 & $0.95-1.08$ \\
\hline $\begin{array}{l}\text { Number of days per week seeing } \\
\text { patients }\end{array}$ & 0.75 & $0.46-1.24$ \\
\hline \multicolumn{3}{|l|}{ Vignette-patient characteristics } \\
\hline \multicolumn{3}{|l|}{ Age, y } \\
\hline 72 & 1 (Ref) & \\
\hline 84 & $3.22^{\mathrm{b}}$ & $1.43-7.25$ \\
\hline \multicolumn{3}{|l|}{ Cognitive impairment } \\
\hline No & 1 (Ref) & \\
\hline Yes & $3.13^{b}$ & $1.36-7.20$ \\
\hline \multicolumn{3}{|l|}{ Functional impairment } \\
\hline No & 1 (Ref) & \\
\hline Yes & $2.48^{\mathrm{b}}$ & $1.12-5.46$ \\
\hline
\end{tabular}

Abbreviation: aOR, adjusted odds ratio.

a Model A, $n=279 ; 26$ observations not included due to missing information for response and exploratory variables.

${ }^{\mathrm{b} P} P<.05$.

'Model $B, n=161$; model includes only those observations where chemotherapy was recommended. vignettes, despite their limited confidence in assessing for functional and cognitive issues in clinical practice, suggest the importance of routine use of GA in clinical practice to guide management decisions for cancer treatment and nononcologic interventions.

Limitations should be considered when evaluating the results of this study. This was a decision-making study using hypothetical vignettes, not decisions for real patients. Nevertheless, studies have shown that decisions made for vignettes were highly correlated with decisions made during patient encounters. ${ }^{18,49,50}$ Use of vignettes can help elucidate decision-making processes that may not be easily studied in routine practice due to ethical or practical considerations. ${ }^{18,49,50}$ Systematic control of variables of interest provides insight into the specific role of these selected patient factors in the decision to initiate chemotherapy, but does limit inferences for actual practice. Although the response rate for the survey was higher than that of other studies, it was still just $>60 \%$. Because oncologists completed the baseline survey as part of the recruitment procedures for geriatric oncology trials, oncologists who participated may be more sensitive to geriatric issues than those who did not participate. We did not collect detailed information on practice characteristics (eg, access to geriatricians). Despite limitations, this study has a significant strength in that it involved community oncologists from different practices and regions of the country, which improves generalizability.

\section{Conclusions}

With the use of randomized vignettes, we found that chronologic age was associated with treatment decisions. Despite their lack of confidence in certain areas of geriatric assessment and evaluation, the oncologists incorporated geriatric factors into treatment decision-making. Because the current investigation was nested in larger, ongoing multisite geriatric oncology studies, future research will examine community oncologists' decision-making for treatment of "real-world" older patients recruited into the trials. Further work is necessary to evaluate and improve geriatrics education for oncologists. As our population ages, it is increasingly important for oncologists to be able recognize geriatric issues so that appropriate evidence-based treatment is provided to patients who will be helped and not harmed. 
Treatment Decision-Making for Older Patients

\section{References}

1. Smith BD, Smith GL, Hurria A, et al. Future of cancer incidence in the United States: burdens upon an aging, changing nation. J Clin Oncol 2009;27:27582765.

2. Hurria A, Dale W, Mooney M, et al. Designing therapeutic clinical trials for older and frail adults with cancer: U13 conference recommendations. J Clin Oncol 2014;32:2587-2594.

3. Mohile SG, Fan L, Reeve E, et al. Association of cancer with geriatric syndromes in older Medicare beneficiaries. J Clin Oncol 2011;29:1458-1464.

4. Mohile SG, Xian Y, Dale W, et al. Association of a cancer diagnosis with vulnerability and frailty in older Medicare beneficiaries. J Natl Cancer Inst 2009;101:1206-1215.

5. Hurria A, Mohile S, Gajra A, et al. Validation of a prediction tool for chemotherapy toxicity in older adults with cancer. J Clin Oncol 2016;34:23662371 .

6. Wildes TM, Depp B, Colditz G, Stark S. Fall-risk prediction in older adults with cancer: an unmet need. Support Care Cancer 2016;24:3681-3684.

7. Quipourt V, Jooste V, Cottet V, et al. Comorbidities alone do not explain the undertreatment of colorectal cancer in older adults: a French population-based study. J Am Geriatr Soc 2011;59:694-698.

8. O'Neill CB, Baxi SS, Atoria CL, et al. Treatment-related toxicities in older adults with head and neck cancer: a population-based analysis. Cance 2015;121:2083-2089.

9. Zeng C, Wen W, Morgans AK, et al. Disparities by race, age, and sex in the improvement of survival for major cancers: results from the National Cancer Institute Surveillance, Epidemiology, and End Results (SEER) program in the United States, 1990 to 2010. JAMA Oncol 2015;1:88-96.

10. Dale W, Mohile SG, Eldadah BA, et al. Biological, clinical, and psychosocial correlates at the interface of cancer and aging research. J Natl Cancer Inst 2012;104:581-589.

11. Hurria A, Naylor $M$, Cohen HJ. Improving the quality of cancer care in an aging population: recommendations from an IOM report. JAMA 2013;310:1795-1796.

12. Klabunde $\mathrm{CN}$, Ambs A, Keating NL, et al. The role of primary care physicians in cancer care. J Gen Intern Med 2009;24:1029-1036.

13. Hurria $A$, Balducci $L$, Naeim $A$, et al. Mentoring junior faculty in geriatric oncology: report from the Cancer and Aging Research Group. J Clin Onco 2008;26:3125-3127.

14. Moy B, Flaig TW, Muss HB, et al. Geriatric oncology for the 21 st century: a call for action. J Clin Oncol 2014;10:241-243.

15. Repetto L, Fratino L, Audisio RA, et al. Comprehensive geriatric assessment adds information to Eastern Cooperative Oncology Group performance status in elderly cancer patients: an Italian Group for Geriatric Oncology Study. J Clin Oncol 2002;20:494-502.

16. Maggiore RJ, Gorawara-Bhat R, Levine SK, Dale W. Perceptions, attitudes, and experiences of hematology/oncology fellows toward incorporating geriatrics in their training. J Geriatr Oncol 2014;5:106-115.

17. Robinson BE, Barry PP, Renick N, et al. Physician confidence and interest in learning more about common geriatric topics: a needs assessment. J Am Geriatr Soc 2001;49:963-967.

18. Campbell $\mathrm{KH}$, Smith SG, Hemmerich J, et al. Patient and provider determinants of nephrology referral in older adults with severe chronic kidney disease: a survey of provider decision making. BMC Nephrol 2011;12:47.

19. Tilburt JC, Miller FG, Jenkins S, et al. Factors that influence practitioners' interpretations of evidence from alternative medicine trials: a factorial vignette experiment embedded in a national survey. Med Care 2010;48:341-348.

20. Kunins HV, Sohler NL, Roose RJ, Cunningham CO. HIV provider endorsement of primary care buprenorphine treatment: a vignette study. Fam Med 2009;41:722-728.

21. Keating NL, Landrum $M B$, Klabunde $C N$, et al. Adjuvant chemotherapy for stage III colon cancer: do physicians agree about the importance of patient age and comorbidity? J Clin Oncol 2008;26:2532-2537.

22. Mohile SG, Velarde C, Hurria A, et al. Geriatric assessment-guided care processes for older adults: a Delphi consensus of geriatric oncology experts. J Natl Compr Canc Netw 2015;13:1120-1130.

23. Johnson M. Chemotherapy treatment decision making by professionals and older patients with cancer: a narrative review of the literature. Eur J Cance Care (Engl) 2012;21:3-9.

24. Wan-Chow-Wah D, Monette J, Monette M, et al. Difficulties in decision making regarding chemotherapy for older cancer patients: a census of cancer physicians. Crit Rev Oncol Hematol 2011;78:45-58.

25. Karuturi M, Wong ML, Hsu T, et al. Understanding cognition in older patients with cancer. J Geriatr Oncol 2016;7:258-269.
26. Extermann M, Boler I, Reich RR, et al. Predicting the risk of chemotherapy toxicity in older patients: the Chemotherapy Risk Assessment Scale for HighAge Patients (CRASH) score. Cancer 2012;118:3377-3386.

27. Wildes TM, Ruwe AP, Fournier C, et al. Geriatric assessment is associated with completion of chemotherapy, toxicity, and survival in older adults with cancer. J Geriatr Oncol 2013;4:227-234.

28. Conroy $\mathrm{T}$, Desseigne $\mathrm{F}$, Ychou $\mathrm{M}$, et al. FOLFIRINOX versus gemcitabine for metastatic pancreatic cancer. N Engl J Med 2011;364:1817-1825.

29. Gourgou-Bourgade S, Bascoul-Mollevi C, Desseigne F, et al. Impact of FOLFIRINOX compared with gemcitabine on quality of life in patients with metastatic pancreatic cancer: results from the PRODIGE 4/ACCORD 11 randomized trial. J Clin Oncol 2013;31:23-29.

30. Von Hoff DD, Ervin T, Arena FP, et al. Increased survival in pancreatic cancer with nab-paclitaxel plus gemcitabine. N Engl J Med 2013;369:1691-1703.

31. Tabernero J, Chiorean EG, Infante JR, et al. Prognostic factors of survival in a randomized phase III trial (MPACT) of weekly nab-paclitaxel plus gemcitabine versus gemcitabine alone in patients with metastatic pancreatic cancer. Oncologist 2015;20:143-150.

32. Amireault C, Beaudet J, Gaudet G, et al. FOLFIRINOX in the real-world setting: the multicentric experience of six Canadian institutions [abstract]. J Clin Oncol 2014;32(Suppl):Abstract 367.

33. Stone ME, Lin J, Dannefer D, Kelley-Moore JA. The continued eclipse of heterogeneity in gerontological research. J Gerontol B Psychol Sci Soc Sci 2017;72:162-167.

34. Berry MF, Worni M, Pietrobon R, et al. Variability in the treatment of elderly patients with stage IIIA (N2) non-small-cell lung cancer. J Thorac Oncol 2013;8:744-752.

35. Wright J, Doan T, McBride R, et al. Variability in chemotherapy delivery for elderly women with advanced stage ovarian cancer and its impact on survival. Br J Cancer 2008;98:1197-1203.

36. Alliot C. Undertreatment of breast cancer in elderly women: contribution of a cancer registry. J Clin Oncol 2005;23:4800-4801; author reply 4801-4802.

37. Lee $\mathrm{IH}$, Hayman JA, Landrum $\mathrm{MB}$, et al. Treatment recommendations for locally advanced, non-small-cell lung cancer: the influence of physician and patient factors. Int J Radiat Oncol Biol Phys 2009;74:1376-1384.

38. Mohile S, Dale W, Hurria A. Geriatric oncology research to improve clinical care. Nat Rev Clin Oncol 2012;9:571-578.

39. Kanesvaran R, Li H, Koo KN, Poon D. Analysis of prognostic factors of comprehensive geriatric assessment and development of a clinical scoring system in elderly Asian patients with cancer. J Clin Oncol 2011;29:3620-3627.

40. Palumbo A, Bringhen S, Mateos MV, et al. Geriatric assessment predicts survival and toxicities in elderly myeloma patients: an International Myeloma Working Group report. Blood 2015;125:2068-2074.

41. Hurria A, Wildes T, Blair SL, et al. Senior Adult Oncology, Version 2.2014: Clinical Practice Guidelines in Oncology. J Natl Compr Canc Netw 2014;12:82-126

42. Hurria A, Gupta S, Zauderer M, et al. Developing a cancer-specific geriatric assessment: a feasibility study. Cancer 2005;104:1998-2005.

43. Hurria A, Akiba C, Kim J, et al. Reliability, validity, and feasibility of a computer-based geriatric assessment for older adults with cancer. J Oncol Pract 2016;12:e1025-1034.

44. McCleary NJ, Wigler D, Berry D, et al. Feasibility of computer-based selfadministered cancer-specific geriatric assessment in older patients with gastrointestinal malignancy. Oncologist 2013;18:64-72.

45. Williams GR, Deal AM, Jolly TA, et al. Feasibility of geriatric assessment in community oncology clinics. J Geriatr Oncol 2014;5:245-251.

46. Caillet $\mathrm{P}$, Canoui-Poitrine F, Vouriot J, et al. Comprehensive geriatric assessment in the decision making process in elderly patients with cancer: ELCAPA study. J Clin Oncol 2011;29:3636-3642.

47. Hamaker ME, Schiphorst AH, ten Bokkel Huinink D, et al. The effect of a geriatric evaluation on treatment decisions for older cancer patients-a systematic review. Acta Oncol 2014;53:289-296.

48. Magnuson $\mathrm{A}$, Allore $\mathrm{H}$, Cohen $\mathrm{HJ}$, et al. Geriatric assessment with management in cancer care: current evidence and potential mechanisms for future research. J Geriatr Oncol 2016;7:242-248.

49. Peabody JW, Luck J, Glassman P, et al. Comparison of vignettes, standardized patients, and chart abstraction: a prospective validation study of 3 methods for measuring quality. JAMA 2000;283:1715-1722.

50. Peabody JW, Luck J, Glassman P, et al. Measuring the quality of physician practice by using clinical vignettes: a prospective validation study. Ann Intern Med 2004;141:771-780. 